\title{
Differentiating tuberculous pleuritis from other exudative lymphocytic pleural effusions
}

\author{
Pichaya Petborom, Bothamai Dechates, Panunat Muangnoi \\ HRH Princess Maha Chakri Sirindhorn Medical Center, Department of Internal Medicine, Faculty of Medicine, Srinakharinwirot University, \\ Bangkok, Thailand \\ Contributions: (I) Conception and design: P Petborom, B Dechates; (II) Administrative support: P Petborom, B Dechates; (III) Provision of study \\ materials or patients: P Petborom, B Dechates; (IV) Collection and assembly of data: B Dechates; (V) Data analysis and interpretation: P Petborom, \\ B Dechates; (VI) Manuscript writing: All authors; (VII) Final approval of manuscript: All authors. \\ Correspondence to: Pichaya Petborom, MD. HRH Princess Maha Chakri Sirindhorn Medical Center, Department of Internal Medicine, Faculty of \\ Medicine, Srinakharinwirot University, Rangsit-Nakornnayok Road, Ongkarak district Nakornnayok Province, Bangkok 26120, Thailand. \\ Email: pichaya@g.swu.ac.th.
}

Background: Recently, the combination of clinical and pleural fluid data can be used to calculate a score which helps facilitate differential diagnosis between tuberculous pleuritis (TBP) and No-TBP effusions. However, a reliable determination of adenosine deaminase (ADA) remains difficult to obtain in Thailand. Therefore, the aim of our study was set out to develop a scoring which makes use of clinical and pleural fluid data.

Methods: A retrospective study involved 15 patients with TBP and 41 patients with no-TBP. The clinical and pleural fluid data of all patients from January 1, 2011, 32 to December 31, 2014, were collected. The diagnostic sensitivity, specificity, positive and negative predictive value were calculated.

Results: The parameters were superior in detecting TBP, including the ADA $\geq 17.5 \mathrm{U} / \mathrm{L}$, In scoring I $\left[\mathrm{ADA} \geq 40 \mathrm{U} / \mathrm{L}\right.$, age $<35$ years, temperature $\geq 37.8{ }^{\circ} \mathrm{C}$, and $\left.\mathrm{RBC}<5 \times 10^{\circ} / \mathrm{L}\right]$ as $\geq 1.5$ points, and scoring II [no previous history of cancer, age $<35$ years, temperature $\geq 37.8{ }^{\circ} \mathrm{C} \mathrm{RBC}<5 \times 10^{9} / \mathrm{L}$, pleural protein $\geq 50 \mathrm{~g} / \mathrm{L}$, and $\mathrm{LDH}$ ratio $\geq 2.2]$ as $\geq 4.5$ points, since the area under curve (AUC) $74.0 \%, 74.0 \%$, and $81.0 \%$, sensitivity $73.3 \%, 73.3 \%$, and $71.4 \%$, and specificity $68.7 \%, 62.5 \%$, and $71.1 \%$, respectively). Moreover, no previous history of cancer and lower $\mathrm{RBC}<5 \times 10^{9} / \mathrm{L}$ indicated sensitivity (90.6\% and $65.5 \%$ ), and specificity $(70.0 \%$ and $44.4 \%)$, respectively. Summated scores of $\geq 5$ points in model 1 and $\geq 6$ points in model 2 yielded measures of sensitivity (46.7\% and $57.1 \%$ ), and specificity ( $84.4 \%$ and $80.5 \%$ ), respectively.

Conclusions: The high pleural fluid ADA, high scores model 1, high scores model 2, lower RBC, and no previous history of cancer may help to categorize patients into probable TBP for further clinical decisionmaking.

Keywords: Pleural effusion; tuberculosis; malignancy; adenosine deaminase

Submitted Dec 01, 2019. Accepted for publication Jul 28, 2020.

doi: 10.21037/apm-19-394

View this article at: http://dx.doi.org/10.21037/apm-19-394

\section{Introduction}

Tuberculous pleuritis (TBP) is the second common form of extrapulmonary tuberculosis as well as the main cause of pleural effusion in many countries (1). The diagnosis of tuberculous pleuritis or malignant pleural effusion should be considered in any patient with exudative lymphocytic pleural effusion and need further investigation, such as acid-fast bacilli staining in pleural fluid and sputum, pleural fluid culture and cytology, pleural biopsy culture and histology (2). Some investigations have a limitation, acid-fast bacilli staining and cultures of pleural fluid 
from the majority of patients are negative. Moreover, microbiological results in taking a time that a clinical decision for management has generally been made before the organism is identified. A combination of pleural biopsy culture and histology increases the diagnostic yield in up to $90 \%$ but this approach is invasive $(3,4)$. On the other hand, the diagnostic sensitivity of fluid cytology for pleural malignancy is only average $62 \%$ (5). Four metaanalyses demonstrated the uniformly high diagnostic performance of pleural fluid Adenosine deaminase (ADA) in tuberculous pleurisy, which showed $92 \%$ of sensitivity and $90 \%$ of specificity (6). The most widely accepted cutoff value for pleural fluid ADA is $40 \mathrm{U} / \mathrm{L}$ (7). High pleural fluid ADA has also been reported in malignancies (e.g., lymphomas, bronchoalveolar carcinoma, mesothelioma), infectious diseases (e.g., mycoplasma and chlamydia pneumonia, paragonimiasis, infectious mononucleosis, and histoplasmosis), and connective tissue diseases (e.g., rheumatoid arthritis, systemic lupus erythematosus) (7). Moreover, several previous studies have evaluated the performance of Xpert MTB/RIF assay using pleural fluid. Overall, these studies showed limited accuracy with sensitivity ranging from $15 \%$ to $44 \%(8,9)$. Furthermore, some investigations such as ADA level, Xpert MTB/RIF assay, and pleural biopsy are not available in general hospitals. Recently, The combination of clinical (age, temperature, history of malignancy) and pleural fluid [pleural fluid red blood cell count (RBC), protein, adenosine deaminase (ADA), serum lactate dehydrogenase ratio $(\mathrm{LDH})$ ratio] data can be used to calculate a score which can help facilitate differential diagnosis between TBP and No-TBP effusions $(2,10,11)$. However, a reliable determination of ADA remains difficult to obtain in Thailand. Therefore, the aim of our study was set out to develop a scoring which makes use of clinical and pleural fluid data for differential diagnosis of TBP and No-TBP. We present the following article in accordance with the STROBE Reporting Checklist (available at http://dx.doi. org/10.21037/apm-19-394).

\section{Methods}

\section{Study design}

This retrospective study analyzed the case records of all patients with a diagnosis of TBP or malignant pleural effusion at HRH Princess Maha Chakri Sirindhorn Medical Center, Thailand, from January 1, 2011, to December 31,
2014. The participants were selected from the patients who had a lymphocytic exudative pleural effusion, were diagnosed with a standard technique such as Ziehl-Neelsen stains or Lowenstein cultures of pleural fluid/sputum or pleural biopsy, the first pleural effusion results were only used for statistical analysis, and aged more than 18 years. Moreover, the authors were excluded from the study if patients had an incomplete blood sample or pleural fluid parameters.

\section{Data collection}

We collected data regarding basic demographics such as age, gender, tobacco used, occupation, underlying diseases, previous history of cancer and stage of cancer, clinical symptoms/duration (fever, cough, dyspnea, loss of appetite, and weight loss), and pleural fluid parameters such as the site of pleural effusion (right, left or bilateral), volume of pleural effusion, pleural fluid $\mathrm{pH}$, glucose, protein, lactate dehydrogenase (LDH), red blood cells (RBC), white blood cell (WBC), percentage of leukocytes, percentage of neutrophils or lymphocytes, and pleural to serum ratios for protein and $\mathrm{LDH}$, and ADA level.

\section{Diagnosis of tuberculous pleural effusion}

In this present study, the pleural effusions were examined tuberculous if (I) Ziehl-Neelsen stains or Lowenstein cultures of pleural fluid or pleural sputum; (II) pleural biopsy in the parietal pleura indicated caseous granuloma; (III) the patients had an exudative lymphocytic effusion with ADA level more than $40 \mathrm{U} / \mathrm{L}$; (IV) exudative lymphocytic pleural effusion that excluding other causes and effusion resolved after treatment with anti-TB drugs. Finally, the patients with malignant pleural effusion were diagnosed with positive pleural fluid cytology or positive malignant cells in pleural biopsy specimens.

\section{Calculated scoring}

The authors used the scoring model for predictive of TBP effusions based on the previous study (2). In the previous study showed that the combination of clinical data such as age $<35$ years, temperature $\geq 37.8^{\circ} \mathrm{C}$, and no previous history of malignancy, and pleural fluid chemistry profile such as adenosine deaminase $\geq 40 \mathrm{U} / \mathrm{L}$, pleural fluid red blood cell count $<5 \times 10^{9} / \mathrm{L}$, pleural protein $\geq 50 \mathrm{~g} / \mathrm{L}$, and pleural fluid to serum lactate dehydrogenase ratio $\geq 2.2$ into a score- 
based model can facilitate differential diagnosis between tuberculous and malignant effusions. When we applied to discriminate tuberculous from malignant effusions, the scoring system in model 1 [adenosine deaminase $\geq 40 \mathrm{U} / \mathrm{L}$ (5 points); age $<35$ years ( 2 points); temperature $\geq 37.8{ }^{\circ} \mathrm{C}$ ( 2 points); pleural fluid red blood cell count $<5 \times 10^{9} / \mathrm{L}(1$ point $\left.)\right]$ had an area under the receiver operating characteristic (ROC) curve of 0.987 (95\% CI: 0.976-0.999). On the other hand, the score-based model 2 [no previous history of malignancy ( 3 points); age $<35$ years ( 2 points); temperature $\geq 37.8^{\circ} \mathrm{C}$ ( 2 points); pleural fluid red blood cell count $<5 \times 10^{9} / \mathrm{L}$ ( 1 point); pleural protein $\geq 50 \mathrm{~g} / \mathrm{L}$ (1 point); and pleural fluid to serum lactate dehydrogenase ratio $\geq 2.2$ ( 1 point)] had an area under the ROC curve of 0.982 (95\% CI: 0.968-0.995). However, in the present study, the calculations ScoreAdap I $\geq 5$ points was performed using by model 1 and also calculated ScoreAdap II $\geq 6$ points using by model 2 of ADA in the previous study.

\section{Sample size}

The sample size was calculated by STATA version 14.0. A previous study has reported that the proportion of patients with tuberculous pleural effusion was 15.5 (12). The value of $Z$ was set at 1.96. The precision for this estimate was $10 \%$. The authors also calculated for a $10 \%$ drop-out rate. Thus, the calculated sample size was 56 patients in the present study.

\section{Ethics statement}

The present study was approved by the ethics committee of Srinakharinwirot University, Thailand (SWUEC/ E-073/2558). Informed consent was waived because the study was retrospective in design. This study was conducted in accordance with the Declaration of Helsinki (as revised in 2013). Individual patient data were anonymized and stored in an encrypted computer.

\section{Statistical analysis}

All statistical analyses were conducted using SPSS version 22.0 (IBM Corp., Armonk, NY, USA). Demographics data, clinical data and pleural fluid chemistry profile of all categorical variables were reported as number and percentage, meanwhile, mean and standard deviation were used to describe continuous variables. The diagnostic sensitivity, specificity, positive predictive value (PPV), and negative predictive value (NPV) were calculated. We decided the optimal cutoff points of the highest diagnostic accuracy by using receiver-operating-characteristics (ROC) analysis. The two-sided analyses with a p-value less than 5 percentages were considered statistically significant.

\section{Results}

From January 1, 2011, to December 31, 2014, 205 patients had pleural fluid analysis at HRH Princess Maha Chakri Sirindhorn Medical Center. We selected 56 patients who were compatible with the inclusion criteria and excluded 149 patients.

\section{Baseline characteristics}

All of 56 participants were 15 patients with TBP and 41 patients with No-TBP (27 patients with malignancy and 14 unknown patients) (Figure 1). All 15 patients with confirmed TBP; a pleural biopsy is the most commonly diagnosed in 8 patients. Most patients (20/41) with NoTBP were diagnosed by pleural effusion cytology method. Table 1 showed the clinical and pleural fluid data of TBP and No-TBP. There was no significant difference in all the clinical data (age, gender, tobacco used, fever, cough, dyspnea, weight loss, and anemia) and pleural fluid test evaluated, except for both of the previous history of cancer and pleural fluid ADA level $(\mathrm{P}$ value $=0.001,0.010$, respectively).

\section{Predictors of tuberculous pleuritis}

Our study showed that five explanatory factors predicted TBP (Table 2): ADA level $\geq 17.5 \mathrm{U} / \mathrm{L}$, scoring I (ADA $\geq 40 \mathrm{U} / \mathrm{L}$, age $<35$ years, temperature $\geq 37.8^{\circ} \mathrm{C}$, and $\mathrm{RBC}$ $<5 \times 10^{9} / \mathrm{L}$ ) as $\geq 1.5$ points, scoring II (no previous history of cancer, age $<35$ years, temperature $\geq 37.8^{\circ} \mathrm{C}, \mathrm{RBC}<5 \times 10^{9} / \mathrm{L}$, pleural protein $\geq 50 \mathrm{~g} / \mathrm{L}$, and $\mathrm{LDH}$ ratio $\geq 2.2$ ) as $\geq 4.5$ points, yielded measures of the area under curve (AUC) $74.0 \%, 74.0 \%$, and $81.0 \%$, fair sensitivity $73.3 \%, 73.3 \%$, $71.4 \%$, fair specificity $68.7 \%, 62.5 \%, 84.4 \%$, PPV $15.0 \%$, $41.9 \%$, 48.7\%, NPV 86.0\%, 86.3\%, 87.1\%, respectively. Moreover, when we set out to develop a scoring which makes use of clinical and pleural fluid data, summated scores of $\geq 5$ points in model 1 and $\geq 6$ points in model 2 . Our results indicated that the sensitivity, specificity, PPV, and NPV were $46.7 \%, 84.45 \%, 58.3 \%, 77.1 \%$, and $57.1 \%$, $80.5 \%, 61.5 \%, 84.2 \%$, respectively. Moreover, our results 


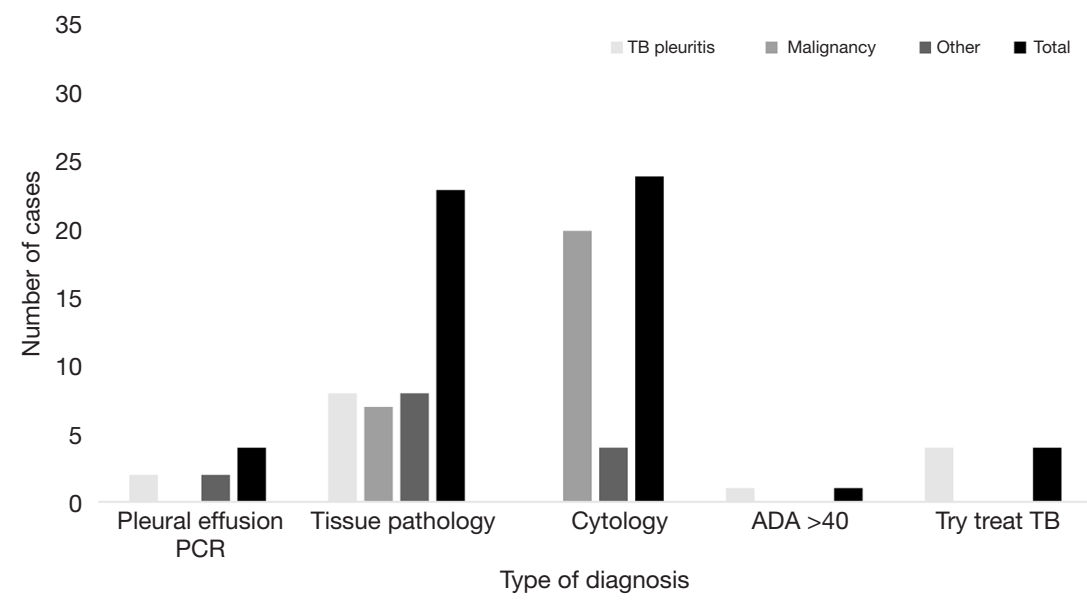

Figure 1 Number of lymphocytic exudative pleural effusions according to type of diagnosis.

demonstrated that seven out of 15 patients $(70.0 \%)$ with TBP, but only $3 / 41$ patients $(30.0 \%)$ with No-TBP had pleural ADA levels $\geq 40 \mathrm{U} / \mathrm{L}(\mathrm{P}=0.007)$ (Figure 2). $8 / 15$ patients with TBP and 10/41 with No-TBP had RBC less than $5 \times 10^{9} / \mathrm{L}$. $7 / 15$ patients with TBP and $17 / 41$ with NoTBP had protein more than $5 \mathrm{~g} / \mathrm{dL}$, in addition, the $6 / 15$ patients with TBP and 6/41 with No-TBP had LDH ratio more than 2.2 U/L. However, when a clinical and pleural fluid data was recorded for inclusion in the analysis, only no previous history of cancer, ADA levels less than $40 \mathrm{U} / \mathrm{L}$, and $\mathrm{RBC}$ less than $5 \times 10^{9} / \mathrm{L}$, but not age, fever, protein, and LDH ratio had significant prevalence rate ratio $(0.312,95 \%$ CI: $0.21-0.47$; 3.238, 95\% CI: $1.552-6.755 ; 3.259,95 \%$ CI: $1.010-10.518$, respectively) (Table 3).

\section{Discussion}

In the present study, we were set out to develop a scoring which makes use of clinical such as age, temperature, history of malignancy and pleural fluid data e.g., pleural fluid RBC, protein, $\mathrm{ADA}$, and $\mathrm{LDH}$ ratio for differential diagnosis of TBP and No-TBP. Our results showed that ADA level $\geq 17.5 \mathrm{U} / \mathrm{L}$, In scoring I as $\geq 1.5$ points, scoring II as $\geq 4.5$ points, summated scores of $\geq 5$ points in model 1 and $\geq 6$ points in model 2, no previous history of cancer, and RBC less than $5 \times 10^{9} / \mathrm{L}$ may help facilitate differential diagnosis between TBP and No-TBP effusions. These findings are almost similar to a few previous studies have evaluated the utility of clinical and pleural fluid data in diagnosing TBP effusion based on predictive models. In a retrospective study from Spain (2), the most powerful predictor of TBP was a score-based model that included model 1 (ADA $\geq 40 \mathrm{U} / \mathrm{L}$, age $<35$ years, temperature $\geq 37.8^{\circ} \mathrm{C}$, and pleural fluid RBC $<5 \times 10^{9} / \mathrm{L}$ ), model 2 identified other predictive parameters: no history of malignancy, pleural protein $\geq 50 \mathrm{~g} / \mathrm{L}$, and pleural fluid to $L D H$ ratio $\geq 2.2$. A comparison between previous study (2) and our study, this score-based model showed a sensitivity ( model 1: $95.0 \%$ vs. $73.3 \%$; model 2: $97.0 \%$ vs. $71.4 \%$ ), specificity (model 1: $94.0 \%$ vs. $62.5 \%$; model 2: $91.0 \%$ vs. $71.1 \%$ ), and area under the ROC curve (model 1: 0.99 vs. 0.74; model 2: 0.98 vs. 0.81) which previous study were higher than our study. Furthermore, our study also indicated that no previous history of cancer had lower sensitivity but higher specificity (46.7\% vs. 100\% and $90.6 \%$ vs. $41 \%$ respectively) and RBC less than $5 \times 10 \% / \mathrm{L}$ had lower sensitivity but higher specificity ( $72.7 \%$ vs. $81 \%$ and $65.5 \%$ vs. $52 \%$ respectively) compared with previous study in Spain (2).

In our present study chosen cutoff point of $17.5 \mathrm{U} / \mathrm{L}$ as a retrospective study in 2013 at Sappasittiprasong Hospital, Ubon Ratchathani, Thailand (13), which showed that the cutoff ADA level >17.5 U/L had higher good diagnostic values (sensitivity $=88.9 \%$ vs. $73.3 \%$, specificity $=73.3 \%$ vs. $68.7 \%$, and area under the $\mathrm{ROC}=0.89$ vs. 0.74 ) among TBP effusion than our present study. On the other hand, the same previous study at Srinagarind Hospital, Khon Kaen, Thailand (14) used the cutoff pleural fluid ADA level of $48 \mathrm{U} / \mathrm{L}$ higher than our present study, giving a higher sensitivity of $80.0 \%$ vs. $73.3 \%$, and higher specificity of $80.5 \%$ vs. $68.7 \%$, respectively. In our study revealed that the minimal level in TBP was only $6.63 \mathrm{U} / \mathrm{L}$ and the maximum level is $69.94 \mathrm{U} / \mathrm{L}$. Differences from the findings 
Table 1 Baseline characteristics

\begin{tabular}{|c|c|c|c|}
\hline Characteristics & TBP $(\mathrm{N}=15)$ & No-TBP $(\mathrm{N}=41)$ & $P$ value \\
\hline Gender & & & 0.062 \\
\hline Male & $10(67.0 \%)$ & $16(40.0 \%)$ & \\
\hline Female & $5(33.0 \%)$ & $25(60.0 \%)$ & \\
\hline Tobacco used & $9(60.0 \%)$ & $12(29.0 \%)$ & 0.101 \\
\hline Fever & $9(60.0 \%)$ & $14(34.0 \%)$ & 0.076 \\
\hline Cough & $9(60.0 \%)$ & $22(54.0 \%)$ & 0.455 \\
\hline Dyspnea & $11(73.0 \%)$ & $30(73.0 \%)$ & 0.637 \\
\hline Lymphadenopathy & $2(13.0 \%)$ & $2(5.0 \%)$ & 0.289 \\
\hline Pleural effusion side (bilateral) & $0(0.0 \%)$ & $6(15.0 \%)$ & 0.138 \\
\hline Pleural effusion (massive) & $6(40.0 \%)$ & $20(49.0 \%)$ & 0.391 \\
\hline Pleural fluid lymphocytes (×106/L) & $78.2 \pm 10.23$ & $76.76 \pm 11.12$ & 0.761 \\
\hline Pleural fluid RBC ( $\left.\times 10^{6} / \mathrm{L}\right)$ & $40,440.55 \pm 92,428.03$ & $77,431.25 \pm 173,504.27$ & 0.913 \\
\hline Pleural fluid protein (g/dL) & $5.27 \pm 1.43$ & $4.92 \pm 1.03$ & 0.319 \\
\hline Pleural fluid LDH (U/L) & $335.73 \pm 110.23$ & $471.67 \pm 150.12$ & 0.640 \\
\hline Pleural fluid glucose (mg/dL) & $125.46 \pm 58.24$ & $104.41 \pm 42.56$ & 0.085 \\
\hline LDH ratio & $2.15 \pm 1.32$ & $2.40 \pm 0.1 .72$ & 0.875 \\
\hline
\end{tabular}

ADA, adenosine deaminase; LDH, lactate dehydrogenase; RBC, red blood cells; TB, tuberculous.

Table 2 Comparative study of pleural fluid ADA and scoring model in the differentiation of TBP from other exudative lymphocytic pleural effusions

\begin{tabular}{lccccc}
\hline Factors & AUC & Sensitivity\% & Specificity\% & PPV\% & NPV\% \\
\hline Pleural fluid ADA (17.5 U/L) & 0.74 & 73.3 & 68.7 & 15.0 & 86.0 \\
Score I (1.5 scores) & 0.74 & 73.3 & 62.5 & 41.9 & 86.3 \\
Score II (4.5 scores) & 0.81 & 71.4 & 71.1 & 48.7 & 87.1 \\
ScoreAdap I ( $\geq 5$ scores) & - & 46.7 & 84.4 & 58.3 & 77.1 \\
ScoreAdap II ( $\geq$ 6 scores) & - & 57.1 & 80.5 & 81.5 & 84.2 \\
\hline
\end{tabular}

ADA, adenosine deaminase; AUC, area under the receiver operating characteristic (ROC) curve; PPV, positive predictive value; NPV, negative predictive value. The authors used the scoring model for predictive of TBP effusions based on the previous study of Porcel et al. (2). 


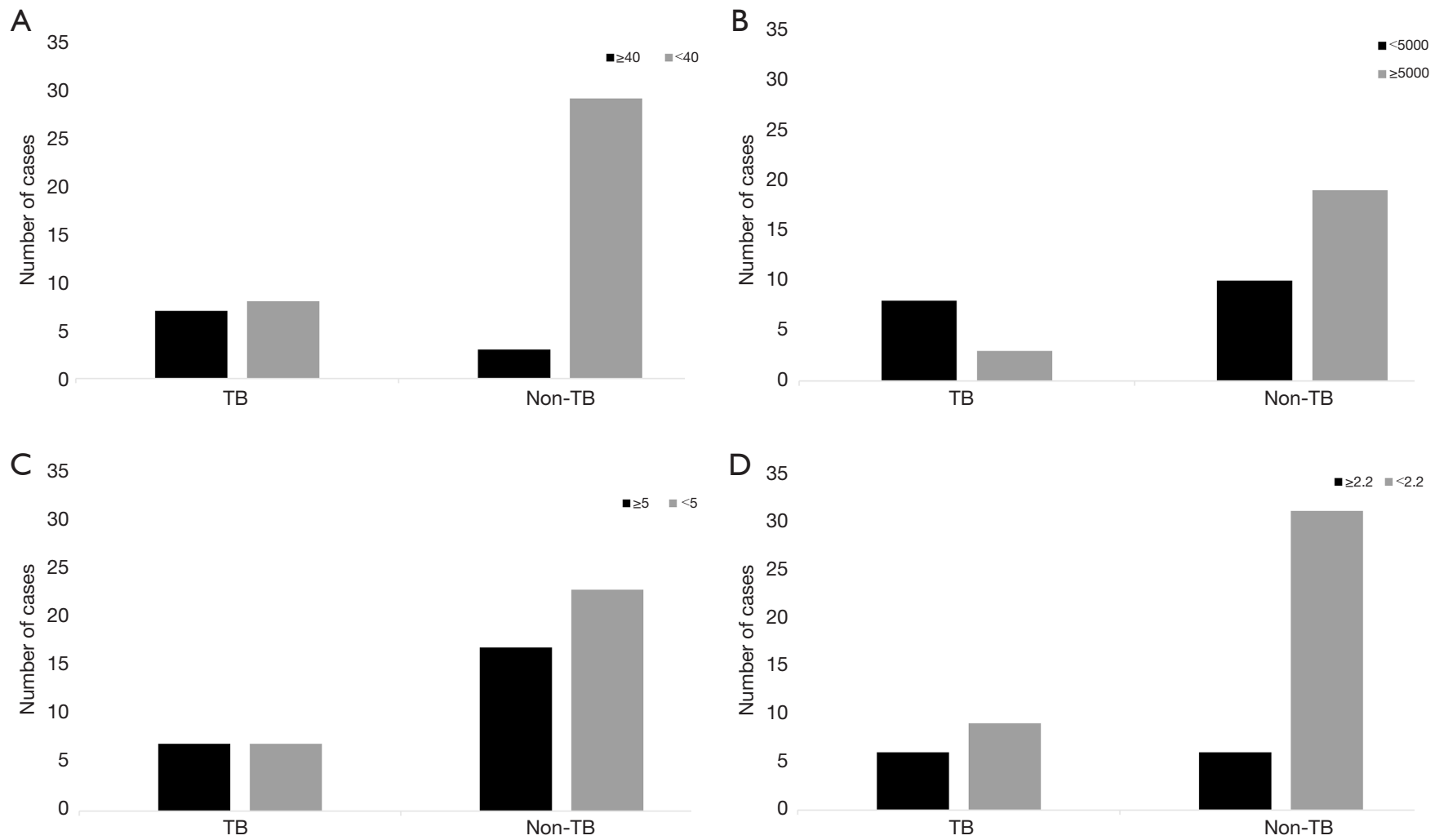

Figure 2 Number of adenosine deaminase, red blood cells, protein, and lactate dehydrogenase according to tuberculous pleuritis group. (A) Number of adenosine deaminase (U/L) according to tuberculous pleuritis group. (B) Red blood cells $\left(\times 10^{6} / \mathrm{L}\right)$ according to tuberculous pleuritis group. (C) Protein (g/dL) according to tuberculous pleuritis group. (D) Lactate dehydrogenase ratio (U/L) according to tuberculous pleuritis group.

Table 3 Comparative study of age, Fever, no history cancer, and pleural fluid parameters in the differentiation of TBP from other exudative lymphocytic pleural effusions

\begin{tabular}{|c|c|c|c|c|c|c|}
\hline Factors & Sensitivity\% & Specificity\% & PPV\% & NPV\% & Prevalence rate ratio $(95 \% \mathrm{Cl})$ & $P$ value \\
\hline Fever & 60.0 & 65.9 & 39.1 & 81.8 & $2.152(0.888-5.216)$ & 0.125 \\
\hline No history of cancer & 46.7 & 90.6 & 70.0 & 78.4 & $0.312(0.210-0.470)$ & 0.001 \\
\hline$A D A \geq 40 \mathrm{U} / \mathrm{L}$ & 46.7 & 90.6 & 70.0 & 78.4 & $3.238(1.552-6.755)$ & 0.007 \\
\hline Protein $\geq 5 \mathrm{~g} / \mathrm{dL}$ & 50.0 & 57.5 & 29.2 & 76.7 & $1.250(0.508-3.074)$ & 0.757 \\
\hline $\mathrm{LDH}$ ratio $\geq 2.2 \mathrm{U} / \mathrm{L}$ & 40.0 & 83.7 & 50.0 & 77.5 & $2.222(0.992-4.979)$ & 0.081 \\
\hline
\end{tabular}

ADA, adenosine deaminase; LDH, lactate dehydrogenase; RBE, red blood cells. The authors used the parameters and scoring model for predictive of TBP effusions based on the previous study of Porcel et al. (2).

of previous studies might due to the different region; the diagnostic criteria for TBP were not the same. However, the previous study (7) suggesting that pleural fluid ADA levels greater than $40 \mathrm{U} / \mathrm{L}$ argue strongly for TBP in areas with high prevalence; in contrast, low levels of pleural ADA have high negative predictive value in low-prevalence. Although 
the current evidence suggests an ADA level can be a useful confirming a diagnosis of TBP (6), the ADA level should be interpreted in parallel with clinical data and the results of conventional tests e.g., microbiologic examination and pleural biopsy. This study is the first study in the central region with a high incidence of TBP, Thailand, as well as the first study set out to develop a scoring based on the previous study (2) which makes use of clinical and pleural fluid data for differential diagnosis of TBP and No-TBP. However, there was some limitation. Firstly, the limitations of this study are its single, tertiary-hospital retrospective study, which makes the results less generalizable. Secondary, the small sample size was a weakness in our results. Thus, the large sample sizes are warranted to further validate our results. Finally, most lost cases were patients who have missing values such as pleural fluid data e.g., $\mathrm{pH}$, pleural fluid glucose.

In conclusion, our present study suggests an ADA level as more than $17.5 \mathrm{U} / \mathrm{L}$, lower RBC, no previous history of cancer, score-based model 1 more than 1.5 points, scorebased model 1 more than 4.5 points, are a relatively sensitive and specific test for the diagnosis of TBP. Therefore, the combination of clinical data and pleural fluid chemistry profile into a score-based model may help to categorize patients into probable TBP for further clinical decisionmaking.

\section{Acknowledgments}

The authors thank Dr.Kitsarawut Khuancharee (Statistical assistant) for the sustained support in conducting this study. Finally, the authors would like to thank the executives of the HRH Princess Maha Chakri Sirindhorn Medical Center, Thailand and faculty of medicine, Srinakharinwirot University for their cooperation with data collection.

Funding: None.

\section{Footnote}

Reporting Checklist: The authors have completed the STROBE Reporting Checklist. Available at http://dx.doi. org/10.21037/apm-19-394

Data Sharing Statement: Available at http://dx.doi. org/10.21037/apm-19-394

Conflicts of Interest: All authors have completed the ICMJE uniform disclosure form (available at http://dx.doi. org/10.21037/apm-19-394). The authors have no conflicts of interest to declare.

Ethical Statement: The authors are accountable for all aspects of the work in ensuring that questions related to the accuracy or integrity of any part of the work are appropriately investigated and resolved. The present study was approved by the ethics committee of Srinakharinwirot University, Thailand (SWUEC/E-073/2558). Informed consent was waived because the study was retrospective in design. This study was conducted in accordance with the Declaration of Helsinki (as revised in 2013).

Open Access Statement: This is an Open Access article distributed in accordance with the Creative Commons Attribution-NonCommercial-NoDerivs 4.0 International License (CC BY-NC-ND 4.0), which permits the noncommercial replication and distribution of the article with the strict proviso that no changes or edits are made and the original work is properly cited (including links to both the formal publication through the relevant DOI and the license). See: https://creativecommons.org/licenses/by-nc-nd/4.0/.

\section{References}

1. Jeon D. Tuberculous pleurisy: an update. Tuberc Respir Dis (Seoul) 2014;76:153-9.

2. Porcel JM, Vives M. Differentiating tuberculous from malignant pleural effusions: a scoring model. Med Sci Monit 2003;9:CR175-80.

3. Valdes L, Alvarez D, San Jose E, et al. Tuberculous pleurisy: a study of 254 patients. Arch Intern Med 1998;158:2017-21.

4. Kirsch CM, Kroe DM, Azzi RL, et al. The optimal number of pleural biopsy specimens for a diagnosis of tuberculous pleurisy. Chest 1997;112:702-6.

5. Antony VB, Loddenkemper R, Astoul P, et al. Management of malignant pleural effusions. Eur Respir J 2001;18:402-19.

6. Liang QL, Shi HZ, Wang K, et al. Diagnostic accuracy of adenosine deaminase in tuberculous pleurisy: a metaanalysis. Respir Med 2008;102:744-54.

7. Porcel JM. Tuberculous Pleural Effusion. Lung 2009;187:263-70.

8. Tortoli E, Russo C, Piersimoni C, et al. Clinical validation of Xpert MTB/RIF for the diagnosis of extrapulmonary tuberculosis. Eur Respir J 2012;40:442-7.

9. Porcel JM, Palma R, Valdes L, et al. Xpert(R) MTB/ 
RIF in pleural fluid for the diagnosis of tuberculosis. Int J Tuberc Lung Dis 2013;17:1217-9.

10. Porcel JM, Aleman C, Bielsa S, et al. A decision tree for differentiating tuberculous from malignant pleural effusions. Respir Med 2008;102:1159-64.

11. Porcel-Pérez JM, Vives Soto M, Esquerda Serrano A, et al. Cuttoff values of biochemical tests on pleural fluid: their usefulness in differential diagnosis of 1,040 patients with pleural effusion. An Med Interna 2004;21:113-7.

12. Garcia-Zamalloa A, Taboada-Gomez J. Diagnostic accuracy of adenosine deaminase and lymphocyte

Cite this article as: Petborom P, Dechates B, Muangnoi P. Differentiating tuberculous pleuritis from other exudative lymphocytic pleural effusions. Ann Palliat Med 2020;9(5):2508-2515. doi: 10.21037/apm-19-394 proportion in pleural fluid for tuberculous pleurisy in different prevalence scenarios. PLoS One 2012;7:e38729.

13. Khow-Ean N, Booraphun S, Aekphachaisawat N, et al. Adenosine deaminase activity level as a tool for diagnosing tuberculous pleural effusion. Southeast Asian J Trop Med Public Health 2013;44:655-9.

14. Reechaipichitkul W, Kawamatawong T, Teerajetgul Y, et al. Diagnostic role of pleural fluid adenosine deaminase in tuberculous pleural effusion. Southeast Asian J Trop Med Public Health 2001;32:383-9. 